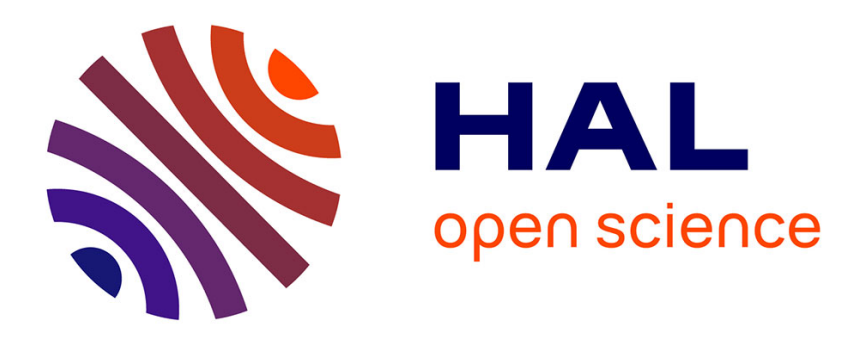

\title{
Culture commune versus émancipation ? Les effets pervers de la canonisation des auteurs philosophiques
}

Sébastien Charbonnier

\section{To cite this version:}

Sébastien Charbonnier. Culture commune versus émancipation ? Les effets pervers de la canonisation des auteurs philosophiques. Carrefours de l'éducation, 2012, 33 (1), 10.3917/cdle.033.0115 . hal01663458

\section{HAL Id: hal-01663458 https://hal.science/hal-01663458}

Submitted on 13 Dec 2017

HAL is a multi-disciplinary open access archive for the deposit and dissemination of scientific research documents, whether they are published or not. The documents may come from teaching and research institutions in France or abroad, or from public or private research centers.
L'archive ouverte pluridisciplinaire HAL, est destinée au dépôt et à la diffusion de documents scientifiques de niveau recherche, publiés ou non, émanant des établissements d'enseignement et de recherche français ou étrangers, des laboratoires publics ou privés. 


\section{CULTURE COMMUNE VERSUS ÉMANCIPATION ? LES EFFETS PERVERS DE LA CANONISATION DES AUTEURS PHILOSOPHIQUES}

Sébastien Charbonnier

Armand Colin | «Carrefours de l'éducation »

2012/1 n³3 | pages 115 à 130

ISSN 1262-3490

ISBN 9782200927707

Article disponible en ligne à l'adresse :

https://www.cairn.info/revue-carrefours-de-l-education-2012-1-page-115.htm

\section{Pour citer cet article :}

Sébastien Charbonnier, « Culture commune versus émancipation ? Les effets pervers de la canonisation des auteurs philosophiques », Carrefours de l'éducation 2012/1 $\left(\mathrm{n}^{\circ} 33\right)$, p. 115-130.

DOI 10.3917/cdle.033.0115

Distribution électronique Cairn.info pour Armand Colin.

(C) Armand Colin. Tous droits réservés pour tous pays.

La reproduction ou représentation de cet article, notamment par photocopie, n'est autorisée que dans les limites des conditions générales d'utilisation du site ou, le cas échéant, des conditions générales de la licence souscrite par votre établissement. Toute autre reproduction ou représentation, en tout ou partie, sous quelque forme et de quelque manière que ce soit, est interdite sauf accord préalable et écrit de l'éditeur, en dehors des cas prévus par la législation en vigueur en France. Il est précisé que son stockage dans une base de données est également interdit. 


\section{Sébastien Charbonnier}

seb.charb@free.fr

\section{CULTURE COMMUNE VERSUS ÉMANCIPATION?} LES EFFETS PERVERS
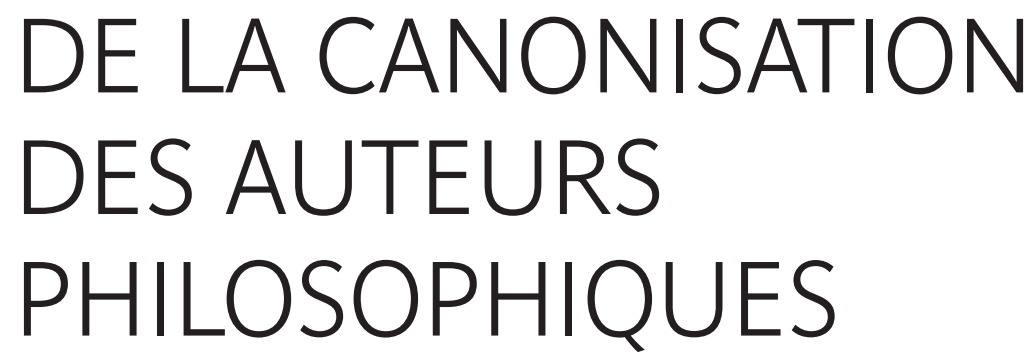

'idéal d'une culture commune semble aller de soi dans la perspective d'une instruction socialisante et émancipatrice : quel meilleur moyen pour penser ensemble que l'acquisition de repères communs depuis lesquels la construction d'idées neuves et la vigilance citoyenne pourront s'exercer au maximum ? En prenant comme objet d'analyse l'enseignement obligatoire de la philosophie dans les classes de terminale générales et technologiques, je voudrais essayer de complexifier cette fausse évidence. Un tel enseignement est paradigmatique puisqu'il s'est pensé continûment, au cours de son histoire, comme permettant de «former l'esprit critique » des futurs citoyens. Or, les évolutions de la discipline depuis un siècle ont fait se cristalliser un corpus d'auteurs loués pour leurs qualités remarquables de penseurs... Mais loin de fonctionner comme « réservoir » d’idées rationnelles susceptibles d'être réappropriées par les élèves en vue d'un exercice de la pensée critique, la canonisation des auteurs philosophiques fonctionne, en bien des points, à rebours des objectifs prêtés à l'enseignement de la philosophie.

Le paradoxe pourrait s'exprimer ainsi : la mise en forme des armes de la pensée critique (établissement d'un corpus à enseigner) constitue en même temps un obstacle à la mise en pratique de ces outils critiques. Autrement dit, il semble- 


\section{CULTURE COMMUNE VERSUS ÉMANCIPATION?}

rait que la volonté d'établir une liste de " monuments libérateurs » pour les jeunes individus formés par l'école sert moins ces derniers que les monuments eux-mêmes - et encore ! La canonisation, en tant qu'elle décide de ce qu'est la culture émancipatrice - au sens de la Bildung - vient entraver l'efficace même de la culture en prétendant la défendre et la valoriser. Le présent article essaie de comprendre cet effet réversif afin de mieux dégager les conditions de possibilité d'un certain usage de la culture qui distribue réellement des puissances encapacitantes pour les individus plus qu'elle ne les rend impuissants.

\section{L'OBJECTIF MANQUÉ DE LA CANONISATION : LUTTER CONTRE LA «BARBARIE »}

Alors que les professeurs de philosophie ont été de plus en plus nombreux au cours du xxe siècle (on passe de 200 avant la Seconde Guerre mondiale à plus de 4000 à la fin du siècle), l'identité de la discipline s'est faite autour d'une liste toujours plus large d'auteurs. Unique moyen de « mettre d'accord » des affinités divergentes, la liste rhapsodique constitue une couverture d'autant plus consensuelle qu'elle est vaste. Dans le nouveau programme de 2003, pas moins de cinquante-sept philosophes sont officiellement canonisés. ${ }^{1}$ Or les études sur la canonisation en philosophie sont rarissimes. ${ }^{2}$

Pour comprendre les effets et propriétés de la canonisation, on peut se reporter au travail pionnier du romaniste allemand Ernst Robert Curtius. À la fin des années trente, il entreprend une vaste enquête qui devait s'intituler à l'origine Culture européenne. ${ }^{3}$ Curtius dégage les origines païennes du canon - liées au classicisme, ses vertus d'excellence, sa figure d'élite sociale ${ }^{4}$ - et surtout ses origines chrétiennes - problématique du canon biblique. L'équation est simple: en canonisant, on réifie, dès lors le canon devient un problème d'héritage. Le mot-clé est lâché: le canon induit des processus de transmission d'héritage dont

1. Cf. Bulletin Officiel du 19 juin 2003.

2. Un texte précurseur est celui de Kuklick B. (1984). Seven Thinkers and How they Grew : Descartes, Spinoza, Leibniz; Locke, Berkeley, Hume; Kant. In Rorty R., Schneewind J.B. et Skinner Q. (éd.). Philosophy in History. Essays on the Historiography of Philosophy. Cambridge: Cambridge University Press, p.125-139. Sur les amours doxographiques dans l'université française, cf. Soulié S. (1995). Anatomie du goût philosophique. Actes de la recherche en sciences sociales, n¹09, p.3-28. Cette enquête porte moins sur le processus de canonisation en lui-même que sur les effets distinctifs des hiérarchies subtiles au sein du canon philosophique.

3. Curtius E.R. (1986) [1948]. La Littérature européenne et le Moyen Âge latin. Paris: PUF.

4. Dans la constitution civile de Servius Tullius, classici désignait les citoyens de premières classes, suffisamment fortunés pour payer l'impôt. Les classiques formaient l'élite sociale. Curtius développera dans une autre enquête, Besitz und Bildung, ce lien ténu entre la culture et la propriété. 
l'école deviendra le moteur essentiel. Dès lors, dans quelle mesure le canon vat-il demeurer compatible avec la perspective de libération de l'apprentissage du philosopher?

Voyons quelles sont les propriétés du canon dégagées par Curtius. Tout d'abord, la tradition est considérée comme le matériau vital de la vie spirituelle dont le canon constitue la substance précieuse, la quintessence. L'intérêt de Curtius est de révéler la vérité de tout canon, l'essentialisme : il existe de " grandes » figures culturelles qu'on peut objectiver en un panthéon bon et beau en soi. En effet, dans le contexte historique qui était le sien, Curtius voulait sauver la culture de l'opération d'amnésie mise en place par le nazisme. D'après Christine de Gemeaux, son projet de recherche est né en réaction aux attaques virulentes du IIle Reich contre la culture : face aux tourments des années 1930, il « ressent l'impérieux besoin de réaffirmer les aspects positifs de la tradition [...] Quand tout s'effondre, le canon offre une dernière possibilité d'orientation. $»^{5}$ Le canon est pensé comme une arme contre les «barbares » : il doit permettre de « conserver, de restaurer et de consolider le plus précieux : la conscience de l'Europe ». II faut impérativement à Curtius préserver les origines culturelles de l'Europe: sa tradition topique issue de la rhétorique antique et médiévale. II n'est pas anodin que l'enseignement de la philosophie se soit replié sur son panthéon au fur et à mesure de sa démocratisation, quand florissaient en parallèle les diagnostics sur la « barbarie ». ${ }^{6}$ Curtius est instructif pour nous: il a été un « Kulturkrikiker conservateur » conséquent puisqu'il a « sciemment "instrumentalisé" le canon » face à la " pédagogie moderne à laquelle il reprochait de négliger les éléments vitaux de la tradition discursive. » ${ }^{7}$

Mais le canon est-il si efficace contre la barbarie ? Curtius a-t-il eu raison de voir dans l'immortalisation des "grands » un remède ? Car loin de libérer les individus, le canon procède sur le même mode opératoire que son adversaire la propagande : I'inculcation... II y a un effet paradoxal du canon : Curtius voulait sauver les « plus grands » de la barbarie nazie, mais les effets à long terme de ce «sauvetage dans l'immédiat» se retournent contre les intentions du sauveur. Le sauvetage induit héritage et crée des dispositions rétives au développement de

5. Cf. la mise en contexte historique du travail pionnier sur la canonisation par Gemeaux C. (2007). Canon, archétypes et mémoire culturelle. E.-R. Curtius à la recherche de sens au milieu du xx siècle. Études Germaniques, 62e année/n³, p. 539-542.

6. Cf. par exemple Henry M. (1987). La Barbarie. Paris : Grasset; Mattéi J.-F. (2004). La Barbarie intérieure: essai sur l'immonde moderne. Paris: PUF.

7. Cf. Gemeaux C. (2007). Canon, archétypes et mémoire culturelle. E.-R. Curtius à la recherche de sens au milieu du xx siècle. Études Germaniques, 62e année/n³, p. 541. Le livre de Curtius contre une certaine « pédagogie moderne » est : Curtius E.R. (1932) Deutscher Geist in Gefahr. Stuttgart/ Berlin: Deutsche Verlagsanstalt. 


\section{CULTURE COMMUNE VERSUS ÉMANCIPATION?}

l'esprit critique: si la canonisation sauve les textes de la barbarie, elles ne sauvent pas les individus d'un devenir-barbare à l'encontre des textes.

Pour éclaircir ce paradoxe, on peut dégager trois propriétés essentielles du canon - qui concernent au moins la discipline scolaire nommée « philosophie ». Premièrement, la canonisation est une entreprise de sanctification. Elle a pour effets objectifs de déshistoriciser et d'éterniser le canon; elle a un effet subjectif de dévotion sur les " apprentis-philosophes ». Deuxièmement, la canonisation est une entreprise d'objectivation, de réification. Elle a pour effet objectif de rigidifier le canon; elle a un effet subjectif d'identification des « professeursphilosophes » au canon. Troisièmement, la canonisation est une entreprise de totalisation. Elle a pour effets objectifs de déréaliser le canon et de mutiler la culture; elle a un effet subjectif de routinisation et de précipitation pour les professeurs. Ces trois propriétés dessinent le parcours d'une initiation : la sanctification permet l'intronisation des novices; la réification est le socle de l'adhésion des participants; la totalisation forclôt la mission de perpétuation des experts. Cette initiation s'oppose à la perspective émancipatrice d'une formation. Ces trois propriétés induisent les trois ennemis de la formation : information comme dogme en quoi croire, formatage comme posture inculquée, formalisme comme règles et repères à adopter.

\section{PREMIÈRE PROPRIÉTÉ DU CANON : LA SANCTIFICATION}

La canonisation est une sanctification : dire cela est quasiment une tautologie mais a le mérite de souligner l'origine religieuse de la métaphore et fait directement rentrer dans la dimension initiatique du canon.

La sanctification suppose des personnes habilitées: ce sont les historiens de la philosophie. Ils sont les gardiens qui assurent l'unité du corps philosophique: par-delà les amours de chacun, le rapport à la doxographie devient constitutif de la définition de l'acte de philosopher. Les rapports de jury du CAPES ou de l'agrégation constituent un véritable devoir de mémoire de la profession : la fréquentation personnelle des textes est jugée nécessaire, on se lamente sur les signes d'une connaissance de seconde main, et cetera. Ce fait identitaire devient prépondérant à partir de la seconde moitié du xxe siècle : il est corrélatif de l'accroissement de la liste des auteurs au programme et surtout du choix pédago- 


\section{SÉBASTIEN CHARBONNIER}

gique de revenir à la fréquentation directe des textes. L'histoire de la philosophie devient le dénominateur commun d'un savoir savant dit « philosophique ».8

Des trois propriétés du canon, la sanctification est celle qui fait sentir ses effets en premier : elle concerne avant tout l'intronisation des novices. En effet, les jurys de concours se lamentent souvent sur la dévotion des candidats vis-à-vis des textes philosophiques. En 1929, le rapport de l'agrégation notait à propos d'un sujet sur la liberté : " Les examinateurs de cette composition se seraient attendus sur un problème de cette portée à trouver une réaction plus personnelle, une acceptation moins docile des idées devenues courantes dans l'enseignement. [...] Si l'histoire du problème ne pouvait être tout à fait négligée, il est pourtant fâcheux de voir maintes dissertations dégénérer en une simple revue de doctrine, en un raccourci forcément arbitraire des développements de la philosophie tout entière. ${ }^{9}$ Mais les auteurs du rapport se demandent-ils si ce « défaut » est autre chose qu'un travers anecdotique ? Si les agrégatifs offrent le portrait le plus caricatural qui soit de la philosophie, peut-être est-ce parce qu'ils sont surexposés, par leur projet professionnel, aux dérives scolaires de l'enseignement de la philosophie et notamment aux effets du canon.

Comme pour tout rite d'intronisation, il s'agit de pénétrer un monde à part. L'effet sanctificateur du canon est donc aussi de détacher les futurs professeurs de philosophie du réel. C'est un rapport de 2001 sur l'agrégation de philosophie qui le souligne:

«Un autre risque, tout aussi réducteur, est d'identifier la philosophie à une histoire de la philosophie mal comprise. Car celle-ci se désarme elle-même si elle n'inclut pas la confrontation avec l'histoire des savoirs et des pratiques. Ce repliement sur soi a une conséquence : on parlera d'un tableau qu'on n'a jamais vu, d'une musique qu'on n’a jamais entendue, d'une passion qu'on n'a peut-être jamais éprouvée, et aussi de savoirs qu'on ne maîtrise pas, pour peu que, par chance, un grand auteur nous souffle ce que nous avons à en dire. C'est ainsi que très souvent le réel n'est convoqué qu'à travers des médiations exclusivement philosophiques. Au point qu'on pourrait croire que certains étudiants choisissent de faire de la philosophie pour fuir le réel plutôt que pour le comprendre.»

Et il ajoute quelques lignes plus loin : « il faut bien constater que beaucoup d'étudiants actuels entretiennent un rapport très lointain avec ce que l'ancien

8. Un indice parmi d'autres de ce repli : les auteurs « non philosophes » représentaient $26,5 \%$ des textes donnés au baccalauréat dans la troisième épreuve en 1972 jusqu'à ne représenter plus que 11,9 \% en 1995-1996. Cf. Pinto L. (2007). La Vocation et le métier de philosophe. Paris : Éd. du Seuil, p. 65-67 et p. 74-76.

9. Rapport de l'agrégation de 1929 (1930). Revue universitaire, p. 2 ; cité par Poucet B. (1999). Enseigner la philosophie, 1860-1990. Paris: CNRS Éditions, p. 258. 


\section{CULTURE COMMUNE VERSUS ÉMANCIPATION?}

dispositif nommait logique, sociologie, psychologie. ${\aleph^{10}} \|$ est significatif que ce propos apparaisse dans la section « Enseignement » du rapport; car c'est bien le sens même de l'apprentissage de ces futurs professeurs, destinés à apprendre à d'autres, qui devient paradoxal.

\section{DEUXIÈME PROPRIÉTÉ DU CANON : LA RÉIFICATION}

La canonisation est une réification. Elle évite de se demander : qu'est-ce que la philosophie ? À cette question, la canonisation apporte une réponse immédiate : la philosophie est Platon, Descartes, Kant et est dit corrélativement « philosophe » celui qui possède ce bagage culturel. Au début des années 1990, une Inspectrice Générale peut fixer les objectifs de l'année de Terminale pour l'élève en ces termes: " qu'il connaisse l'essentiel des "grandes" philosophies (Platon, Descartes, Spinoza, Kant, Hegel). »11 Ce rapport totémique à la culture induit par la canonisation devient le principe de l'identité philosophique. C'est ce que Bourdieu appelait la « philosophie objectivée » dont il expliquait qu'elle

"s'impose comme une sorte de monde autonome à ceux qui prétendent entrer en philosophie
et qui doivent non seulement la connaître, en tant qu'élément de culture, mais la reconnaître, en
tant qu'objet de croyance (pré-réflexive), sous peine de s'exclure du champ philosophique. Tous
ceux qui font profession de philosopher ont un intérêt de vie ou de mort en tant que philosophes
à l'existence de ce dépôt de textes consacrés dont la maîtrise plus ou moins complète constitue
l'essentiel de leur capital spécifique. »12

L'enjeu est rien moins que l'identité du corps philosophique : la monstration d'une compétence spécifique garantit l'adhésion comme membre du corps. La clandestinité est désignée sur le mode de la négation: les autres sont des «non philosophes ». Même si le qualificatif ne comporte aucune méchanceté dans l'esprit de ceux qui l'utilisent, il n'en signale pas moins la logique binaire qui structure l'identité philosophique dont la participation au canon est aujourd'hui le principe essentiel.

Cette seconde dimension du canon légitime la propriété du titre de " philosophe ». De ce point de vue, l'histoire de la philosophie fonctionne comme capital culturel devenu vital pour se définir en tant que « philosophe ». La perdu-

10. Pessel A. (2001). Rapport à Monsieur le ministre de l'Éducation nationale sur l'agrégation de philosophie. Documentation française. Mis en ligne sur: http://pedagogie.ac-amiens.fr/philosophie/ philoofficiel/Pessel/sommaire.htm.

11. Best F. (1991). Témoignage. L'École des philosophes, n¹, p. 13.

12. Bourdieu P. (1979). Élements pour une critique "vulgaire" des critiques "pures". Post-scriptum de La Distinction. Paris : Éd. de Minuit, p. 580-581. 


\section{SÉBASTIEN CHARBONNIER}

ration du canon philosophique est fondée sur la discipline qui le crée et l'entretient: I'histoire de la philosophie. Elle est devenue primordiale dans l'identité philosophique au moins à trois titres. D'abord les historiens de la philosophie représentent l'élite universitaire du corps professoral, ils sont donc un modèle ; par voie de conséquence, les étudiants se trouvent prédisposés à éprouver comme intéressants une grande variété de sujets d'histoire de la philosophie, dont l'inventivité et la marginalité ne sont compréhensibles que parce que le marché professionnel du champ philosophique leur est particulièrement favorable; enfin, avec la concurrence pressante des sciences humaines, il semble que la profession se soit retrouvée autour de cette spécialité, la seule qui soit en mesure de marquer la spécificité du discours professoral autour d'une culture commune constituée.

Le professeur de philosophie devient gardien de la vérité historique, souvent scrupuleux à éviter les contresens. Sont ainsi liés maîtrise d'un trésor culturel, possibilité d'une identité corporatiste et bénéfices de la distinction. Un excellent exemple est donné par Michèle Le Doeuff: dans un article érudit, elle fait l'histoire du contresens sur la «morale par provision » de Descartes et montre parfaitement le glissement sémantique de la philosophie scolaire qui transforme l'expression en "morale provisoire ». Elle analyse l'histoire de cette " erreur » et fait la démonstration de son illégitimité. D'un côté, l'article offre une analyse scrupuleuse des tenants et aboutissants de la morale cartésienne; de l'autre, intitulé « En rouge dans la marge », il est une illustration parfaite de la rigueur exégétique dont les professeurs de philosophie se font une «marque de fabrique ». Ainsi érigé en gardien scrupuleux de la tradition philosophique, le professeur se fait le zélé pourfendeur de ces « petites erreurs sacrilèges » : rien ne l'agace plus que ces inexactitudes des élèves - l'enjeu est grand car au travers de ces légères dérives tout le sens philosophique est perdu. Mais derrière cette rigueur salutaire pour la pensée, se cache un impensé que l'auteur explicite dans une conclusion autocritique:

« par cette correction, il s'agit plutôt pour le maître de ré-assurer sa maîtrise, c'est-à-dire d'abord sa différence par rapport à l'élève qui ne se nourrit que d'une sous-culture philosophique, alors que, lui, "connaît ses textes", autrement qu'à travers des ouvrages de seconde main. Si l'altérité (entre lui et l'élève) est ce que souhaite le maître, ce souhait trouve dans la différence de capital culturel l'occasion de satisfactions non-négligeables. $)^{13}$

Plus avant, Michèle Le Doeuff reconnaissait que l'effet d'identification par adhésion au canon a une puissance socialement distinctive indéniable : « le fait

13. Cf. Le Doeuff M. (1997) [1977]. En rouge dans la marge. In GREPH. Qui a peur de la philosophie? Paris : Flammarion, «Champs», p. 416-417. 


\section{CULTURE COMMUNE VERSUS ÉMANCIPATION?}

d'avoir reçu un enseignement de philosophie fonctionne comme symbole de démarcation d'avec "le commun des hommes", manière sublimée de marquer le hiatus entre "l'élite dirigeante" et "le peuple", pour parler comme les théoriciens de la Troisième République.»

D'où cet effet singulier du jeu de langage scolastique : penser avec les philosophes signale moins une interfécondation qu'une obséquence. Ce néologisme résume l'ethos de l'esprit de sérieux: se plier à l'autorité du nom (obséquiosité) et suivre scolairement un ordre de mission (séquence) conduit aux obsèques de la pensée. Dans le régime de l'obséquence, les philosophes deviennent, bien malgré eux, des totems menaçants : ils sont inhibiteurs - « ne pense pas sans les lire $»^{14}$ - et sacrés - «lis-les sans les contredire $»^{15}$ - donc sclérosants - que puis-je avoir encore d'intéressant à dire ? Le rapport à la culture philosophique est donc un souci de préservation et de fidélité : il ne faut pas abîmer ou déformer les idées, la restitution doit être à la fois érudite et précise. Cette attente est typiquement un produit de la scolarisation que les jurys de concours sont les premiers à déceler - bien qu'ils soient, paradoxalement, les premiers à créer cet état de chose. L'attente est un système d'interpassivité : les uns attendent des autres ceci (maîtrise d'un corpus), les autres attendent des uns cela (délivrance d'un titre). Dans cet échange, tout le monde attend et rien ne se passe : c'est le destin de tout conservatisme. Zizek, qui explore le concept d'interpassivité, le définit ainsi : "le fait que quelqu'un soit actif par la médiation d'un autre faisant le travail pour lui - [...] quelqu'un est actif pour assurer la passivité d'un autre $\gg .{ }^{16}$ II est idoine pour la canonisation : celle-ci est un travail effectué par la tradition (et ses gardiens) pour les aspirants professeurs-philosophes qui reçoivent passivement un canon constitué par d'autres; la canonisation est donc une activité qui assure la passivité puisqu'elle préserve du souci d'explorer et de chercher par soi-même les richesses pour nous aujourd'hui de la pensée philosophique.

14. Deleuze résume bien le problème : « L’histoire de la philosophie a toujours été l'agent de pouvoir dans la philosophie, et même dans la pensée. Elle a joué le rôle de répresseur : comment voulezvous penser sans avoir lu Platon, Descartes, Kant et Heidegger, et le livre de tel ou tel sur eux? Une formidable école d'intimidation qui fabrique des spécialistes de la pensée, mais qui fait aussi que ceux qui restent en dehors se conforment d’autant mieux à cette spécialité dont ils se moquent. » - Deleuze G. (1979). Dialogues. Paris : Champs-Flammarion, p. 19-20.

15. Des petits propos comme celui-ci, de la plume d'Alquié, traduisent l'état d'esprit de l'obséquence: «Si on croit pouvoir contredire Descartes ou Kant, c'est qu'on les a mal compris. » - Alquié F. (2000) [1934]. Plans de philosophie générale. Paris : La Table Ronde, p. 9.

16. Zizek S. (2002) [1998]. Le spectre rôde toujours. Paris : Éd. Nautilus, p. 42 sqq. 


\section{TROISIÈME PROPRIÉTÉ DU CANON : LA TOTALISATION}

Pour des raisons sans doute liées à la faible audience de la philosophie, la canonisation de ses auteurs est quasiment uniquement liée à la forme scolaire du savoir - alors que la canonisation peut prendre d'autres formes: noms de rues, noms d'écoles, et cetera. Les outils par excellence de la canonisation sont donc les manuels, les recueils, les anthologies, les collections scolaires en général, et bien sûr les programmes. Ces divers supports créent le délire de totalisation au cœur du canon: le canon condense toute la philosophie, le tout de la philosophie. Le refus d'abandonner cette prétention totalisante explique en grande partie le côté démentiel des programmes de philosophie. La totalisation est la dernière étape chronologique de la canonisation : elle correspond à un effort consensuel pour établir ce qu'il faut transmettre, décision lourde que seuls des sages peuvent prendre. Après l'intronisation des novices et l'adhésion des membres, c'est la mission de perpétuation des experts. Or, Pierre Aubenque signale le dangereux biais de cette attitude: « La tradition transmet et prolonge et, par-là, achève; la tradition est ce qui prend la suite d'un commencement et par là supprime ce qu'il y avait de commençant en lui ; la tradition ne "s'étonne" plus; la tradition résout l'aporie, alors que l'aporie est toujours vécue comme

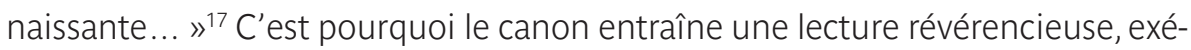
gétique, bref liturgique, dont les présupposés répondent à une logique propre: " assurer aux textes canoniques la fausse éternisation d'un embaumement rituel. $»^{18}$ Initiation, participation, embaumement rituel : de bout en bout le canon respecte son sens religieux littéral.

Les effets sont immédiats : comme le canon est nécessairement clos et limité - sinon ce n'est plus un canon - on répète souvent les mêmes choses, c'est la routinisation; comme le canon est tout de même ambitieux - sinon il serait partial - on doit se précipiter pour parcourir tous les trésors de l'humanité pensante, c'est la précipitation ${ }^{19}$. Les deux sont évidemment liés. C'est parce qu'il faut se précipiter à tout faire qu'on ne peut pas expérimenter différemment : la routinisation est la conséquence d'un cours perfectionné d'année en année, seule solution tenable quand l'expérimentation et le changement sont empêchés par la précipitation. La radicalisation conséquente de cette posture

17. Aubenque P. (1962). Le Problème de l'être chez Aristote. Paris : PUF, p. 506.

18. Bourdieu P. (1997). Méditations pascaliennes. Paris : Éd. du Seuil, p. 59.

19. II est tentant de faire un jeu de mots entre le sens chimique de la précipitation, image suggestive de ce qu'est un canon - œuvres « solides » créées par la réaction entre des génies et leurs thuriféraires avertis -, et la conséquence scolaire de précipitation dans le parcours de ce précipité. 


\section{CULTURE COMMUNE VERSUS ÉMANCIPATION?}

de perpétuation du canon est l'attitude du bibliothécaire de L'Homme sans qualités: ne plus lire aucun livre, mais seulement les registres de sa bibliothèque, pour savoir tout ce qui existe et ainsi mémoriser tout le panthéon des œuvres de la pensée. ${ }^{20}$ Les nombreuses "fiches » faites par les élèves participent de cette logique de non-lecture qu'induit la totalisation du canon. Pierre Bayard a fait une analyse de ce paradoxe: le lecteur insouciant qui navigue d'un livre à l'autre - et les lit ! suprême vice - au gré de son désir est le pire ennemi de la culture. En effet, celui qui est obsédé par la perpétuation du patrimoine culturel doit comprendre que son véritable ennemi est le lecteur parce que ce dernier gaspille son temps à fréquenter directement des œuvres dans leur intégralité, donc voue tout le reste à l'oubli. ${ }^{21}$ Ce manque de temps de la limitée psyché humaine - un individu ne peut pas tout lire - conduit alors le canonisateur à la création d'une « liste des incontournables ».

\section{ANALYSE D'UN PHÉNOMÈNE RÉVÉLATEUR: LE CHOIX DE L'CEUVRE POUR L'ORAL DU BAC}

Après cette analyse des trois propriétés du canon, vérifions empiriquement les effets du programme de philosophie de Terminale sur les amours et la curiosité des «philosophes » français. Ainsi, la nouvelle corrélation établie en 1973 entre l'épreuve d'oral du baccalauréat et l'étude suivie d'une œuvre au cours de l'année condense les trois propriétés de la canonisation et restreint considérablement les effets de la lecture d'un texte philosophique en Terminale.

D'abord, une liste d'auteurs est établie: un canon est donc explicitement ancré/ encré. Ce canon fonctionne par cercle concentrique selon la logique de la participation : certains philosophes se voient attribuer un astérisque. II y a donc les " grands philosophes », plus proches du cœur de la philosophie, et les autres, plus en périphérie. De plus, la fonctionnalité de cette « étude suivie » d'une œuvre est drastiquement encadrée par une finalité évaluative : l'étude en classe d'une œuvre philosophique sert de support à l'épreuve de rattrapage de l'oral du baccalauréat. Les élèves peuvent s'en désintéresser s'ils pensent ne pas aller à l'oral ou du moins ne pas « choisir » philosophie à l'oral. Le choix de l'œuvre à étudier est donc incliné par des paramètres scolaires: le professeur peut être tenté de privilégier les textes « faciles » puisque l'œuvre servira aux élèves scolairement «faibles » en philosophie.

20. Cf. Musil R. (1995) [1930]. L’Homme sans qualités, tome I. Paris : Éd. du Seuil, « Points », p. 581-582.

21. Cf. Bayard P. (2007). Comment parler des livres que l'on n'a pas lus ? Paris : Éd. de Minuit, p. 21-29. 
Le cadre scolaire de la canonisation des textes philosophiques obéit donc avant tout à quelques critères négatifs qu'on peut facilement lister en discutant avec les professeurs de philosophie. II faut exclure : la "densité » philosophique (exemple: Éthique, les trois Critiques); la « technicité » du vocabulaire (exemple: Husserl, Heidegger); la longueur du texte (pas plus d'une centaine de pages, si possible autour de la cinquantaine); la « distance » culturelle (les textes « antiques » et « médiévaux » requièrent des médiations et un temps lourd d'appropriation - ou alors on choisit de les ignorer); la non-rentabilité par rapport au programme (exemple: Esquisse d'une théorie des émotions de Sartre). Au final, on obtient une liste réduite d'œuvres et d'auteurs et surtout la topique du " passage archi-classique » : la Caverne de Platon, les quatre causes chez Aristote, le morceau de cire dans la Seconde Méditation, la séparation des pouvoirs chez Montesquieu, le projet critique de Kant dans la préface à la seconde édition de la première Critique, et cetera. Les trois propriétés du canon sont bien là : sanctification de ces topoi sacrés qui réifie la philosophie en l'incarnant aux yeux des élèves et la totalise en donnant l'illusion qu'il n'y a rien d'autre. Ces textes sont la philosophie, rien que la philosophie et toute la philosophie.

Pour rester dans le vocabulaire religieux, demandons-nous d'où viennent les deux trinités qui se dégagent implicitement dans la culture philosophique scolaire ? De ce que la liste des auteurs est découpée en trois périodes - antique, classique et moderne. ${ }^{22}$ Deux grands éditeurs scolaires consacrent chacun une collection spécifique aux auteurs de philosophie au programme; leurs livres sont donc destinés à l'épreuve de l'oral. L'uniformisation de la canonisation y est flagrante, comme on peut le voir en analysant la concentration de leur effort éditorial sur les deux trinités:

\begin{tabular}{|c|c|c|}
\hline Années 1988-2008 & $\begin{array}{c}\text { "Sainte trinité » } \\
\text { Platon - } \\
\text { Descartes - } \\
\text { Kant }\end{array}$ & $\begin{array}{c}\text { "Trinité dauphine » } \\
\text { Aristote - } \\
\text { Rousseau - } \\
\text { Hegel (cumul) }\end{array}$ \\
\hline $\begin{array}{c}\text { Part quantitative des auteurs jugés } \\
\text { canoniques par le programme de } \\
\text { philosophie }\end{array}$ & $5 \%$ & $10 \%$ \\
\hline Part de l'effort éditorial de HATIER & $52 \%$ & $78 \%$ \\
\hline Part de l'effort éditorial de \\
NATHAN
\end{tabular}

(source: d’après le catalogue des éditeurs et le catalogue de la BNF)

22. Nouvel effet de l'égalitarisme au sein du génial : pour ne pas heurter la sensibilité des dévots, on doit une révérence identique à chaque période de la pensée. 


\section{L'HYPOLEPSE ET LE DESTIN PARADOXAL DES PHILOSOPHES CANONISÉS}

Pour synthétiser ces réflexions sur la canonisation en philosophie, l'ouvrage de Jan Assmann sur La Mémoire culturelle propose des outils décisifs par son analyse du lien entre mémoire et pensée. ${ }^{23}$ À première vue, celle-là semble un obstacle à celle-ci en ce qu'elle enferme le souci de la vérité dans les mailles serrées de la transmission, puissance d'inertie qui freine l'invention donc l'esprit critique. Mais selon Assmann, cette fixation de la mémoire culturelle est nécessaire pour la constitution d'une réalité qui échappe au flux temporel permanent: cette puissance d'épaississement mémoriel du réel est ce qu'Assmann appelle la « cohérence ». Analyser les trois grands modes de transmission de la mémoire culturelle d'Assmann va permettre de montrer que la critique du canon ne débouche pas sur l'oubli, mais permet au contraire de déployer la puissance, pour notre actualité, des œuvres philosophiques passées.

Le premier mode de transmission est la « cohérence rituelle » : celle-ci garantit la continuité de l'identité au prix d'une «compulsion de répétition $»^{24}$ dans les civilisations sans ou avec écriture - par la tradition orale ou les textes sacrés. La mémoire est quasiment mécanique: chaque individu participe de la courroie de transmission identitaire qui repose sur une fidélité à l'origine. Copistes, répétiteurs, enseignants sont les garants de la perpétuation des sources. Dans quelle mesure le souci de l'héritage culturel peut prendre cette forme dans un cours de philosophie en Terminale?

Le second mode est la « canonisation » à proprement parler, c'est-à-dire la constitution de l'identité culturelle à travers la compilation de textes préservés d'une manière ou d'une autre. Elle relève de la « cohérence textuelle ». D'une certaine manière, ce nouveau rapport au passé est libérateur : comme le passé est conservé par l'écriture, une mise à distance est possible, ce que ne permettait pas le rite qui collait toujours au texte et ne le faisait évoluer que par petites variations involontaires - omissions, oublis, erreurs. La réflexion sur le passé est désormais possible grâce au commentaire, qui constitue l'acte majeur du mode de transmission par canonisation. Mais ce mode reste au service du passé, désormais réifié dans la trace écrite : si on peut se distancier de l'origine, on peut aussi juger de la distance : naît donc le mythe du sens originel et les

23. Cf. Assmann J. (2010) [1992]. La Mémoire culturelle. Écriture, souvenir et imaginaire politique dans les civilisations antiques. Paris : Aubier.

24. Ce terme de la psychanalyse freudienne, utilisé par Assmann, insiste sur l'asservissement de la mémoire à la seule conservation répétitive des traces du passé. 
querelles entre les prétendants au «bon sens ». La distanciation permise par l'écriture a cet effet pervers d'aspirer toujours les gloses vers les textes sacrés: l'émancipation créatrice n'est pas réellement possible puisque le canon constitue le foyer autour duquel on tourne. C'est ce qu'Assmann appelle le « blocage canonique » : face à la prolifération des textes et au risque d'une saturation d'information, il faut un blocage canonisant apte à interrompre et à boucler le flux incessant de la tradition écrite. Les textes canoniques sont sacro-saints, ils doivent être transmis de manière littérale, il ne faut rien y ajouter, n'en rien retirer, ne rien modifier. La profondeur prêtée aux textes de philosophie canonisés ne relève-t-elle pas d'un tel mode de transmission ? La quête dévote et répétée de l'intentio operis ne se justifie que si la parole de l'auteur est sacrée : I'interprétation infinie du littéral trouve sa justification dans la croyance que l'auctor est lui-même d'une intelligence infinie - Dieu ou le saint penseur canonisé.

Le troisième mode de transmission de la mémoire culturelle est l'« hypolepse ». Ce terme grec « fait référence au fait, pour un rhapsode, de reprendre à l'endroit où son prédécesseur avait interrompu la récitation ou, pour un orateur, de se rattacher à ce que son prédécesseur a dit. » L'hypolepse est donc une reprise critique du matériau, une innutrition qui induit une transformation. On peut donc dire qu'avec l'hypolepse « il y a conservation et suppression du passé, [...] la conservation du passé va de pair avec sa suppression. $»^{25}$ La fonction de transmission ne désigne plus seulement le contenu, mais surtout le processus énergétique lui-même, la fécondation des idées par transduction. L'hypolepse va donc beaucoup plus loin que la canonisation dans la distanciation au passé, elle engage un rapport critique aux problématiques préexistantes.

Les trois modes de transmission dégagés par Assmann dessinent un effacement progressif de la mémoire entendue comme fidélité à un contenu. La transmission fonctionne de plus en plus comme une libération progressive par rapport à et par la mémoire : celle-ci n'est plus ce qui fige au nom de l'exigence de transmission fidèle mais ce qui nourrit par sa force de fécondation multiple. Avec l'hypolepse, la mémoire devient féconde. Cette libération par l'invention nourrie signifie l'émergence d'un rapport critique à la vérité. Dans la cohérence rituelle, le problème de la connaissance adéquate ne se pose pas puisqu'on colle à ce qui est dit $^{26}$; dans la canonisation, la vérité est détenue par le texte

25. Pouget J.-M. (2007). Le problème de la variation dans la transmission de la pensée philosophique et scientifique : répétition, canonisation, "hypolepse”. Études Germaniques, 62E année/n³, p. 562.

26. Dans Les Maîtres de vérité, Marcel Détienne a bien montré la puissance performative de ce type de discours : le vrai est créé par la Parole de celui qui la profère. Cf. Détienne M. (1967). Les Maîtres de vérité dans la Grèce archaïque. Paris: Maspero, notamment p. 51-81. 


\section{CULTURE COMMUNE VERSUS ÉMANCIPATION?}

sacré qui la dévoile; dans l'hypolepse, les traces du passé fonctionnent comme des signes humains donc rectifiables pour une enquête transgénérationnelle. D’abord absente, ensuite donnée, la vérité devient construite avec l'hypolepse.

L'apprentissage du philosopher semble donc corrélatif d'un rapport hypoleptique au passé. La philosophie est pleine de ce geste critique vis-à-vis de la mémoire culturelle, qui lui assure une transmission-destruction singulière. Cependant, les grands pratiquants de l'hypolepse que sont les philosophes sont paradoxalement salués pour cette liberté de penser, c'est-à-dire canonisés pour avoir maltraité le canon. L'acte hypoleptique de penser devient une pensée canonisée. Prenons deux exemples très célèbres qui se succèdent historiquement. D’abord Aristote: son rapport à ses prédécesseurs - présocratiques et Platon - est typiquement une hypolepse car il conserve leur héritage culturel en les critiquant; en revanche, sa gloire posthume repose le mode canonique de transmission de son œuvre - notamment à l'âge de la scolastique où il est inconcevable de critiquer celui qu'on appelle «le Philosophe ». Contre Aristote ensuite, Galilée, Bacon et Descartes ont voulu faire table rase de la scolastique : face à la postérité anti-aristotélicienne (dans le geste) d'Aristote, il faudra le geste hypoleptique et libérateur de cette trinité anti-aristotélicienne (dans le contenu), donc irrévérencieuse, pour libérer la mémoire culturelle de la philosophie du mode de transmission canonique de la scolastique. C'est pourquoi les post-cartésiens ont créé de grandes œuvres hypoleptiques, transmettant les problèmes philosophiques de la scolastique dans la mesure où ils les détruisaient: Spinoza, Malebranche, Leibniz. Viendra ensuite le temps, notamment dans la philosophie scolaire, de la canonisation de Descartes en philosophe national - qu'il n'a rien fait pour éviter, au contraire. Aujourd'hui, le Discours de la méthode, lieu d'écriture du geste libérateur, est le texte philosophique le plus édité en France ${ }^{27}$ donc probablement un des plus glosés par l'institution scolaire. Par une ironie de l'histoire, les philosophes semblent condamnés à être des Janus de la transmission culturelle: dans leur pratique de la pensée critique, ils ont un rapport hypoleptique avec le passé; dans leur postérité, leurs pensées sont rituellement commentées selon la logique révérencieuse du canon.

Au terme de ce parcours des effets de la canonisation, on prend conscience d'un enfermement dans lequel on se fait prendre inconsciemment lorsqu'est posée la question : « à quoi ça sert d'apprendre à philosopher ? » Aimant la philosophie - qu'est-ce qu'on aime quand on dit ça ? - , on se précipite pour trouver

27. Avec pas moins de 23 éditions de poche entre 1988 et 2008, le Discours de la méthode se place devant le second Discours de Rousseau (18 éditions), l'Apologie de Socrate et le livre VII de La République de Platon (16 éditions chacun) et enfin Qu'est-ce que les Lumières? de Kant (12 éditions). 
une réponse. Mais il faut secouer un peu le problème pour en faire tomber les fruits morts: si l'on conçoit l'intérêt de la philosophie dans une perspective émancipatrice de formation de soi, pourquoi enfermer l'émancipé potentiel dans une position de lecteur passif ? C'est en effet le biais redoutable de la question de la finalité de l'enseignement de la philosophie: Iorsqu'elle repose sur une définition tacite de la philosophie (par canon de « grands » auteurs), elle opère deux clôtures corrélatives. Premièrement, elle force à accepter une définition consensuellement réifiée de la philosophie : la puissance libératrice de la philosophie se cache dans les dialogues de Platon, les œuvres de Descartes ou les opuscules kantiens. Deuxièmement, elle réduit la philosophie à la somme de ses résultats écrits, donc elle omet de la concevoir comme une activité : la puissance libératrice de la philosophie, ce serait seulement la découverte des textes philosophiques - alléluia. Contre cette double réduction, posons que philosopher c'est avant tout et seulement être philosophe. Les rires moqueurs fusent aussitôt : " vous ne voulez pas faire des élèves des Platon ou des Descartes tout de même ? » Une telle objection en dit long sur l'orgueil philosophique volontiers enclin à hisser le titre de " philosophe » au niveau d'une génialité sublime. ${ }^{28}$ Sous couvert de bon sens et d'anti-élitisme, on enferme l'apprentissage du philosopher dans la fréquentation contemplative, passive, et pour tout dire admirative, des « grands » penseurs. Pourtant si philosopher peut être libérateur, c'est uniquement en tant qu'activité donc en tant que création. L'argumentation " anti-élitiste » qui estime que créer des concepts avec les élèves est une tâche absurde dans les conditions concrètes d'enseignement est foncièrement ambiguë. Le constat d'échec provient plutôt de l'inversion de l'implication : c'est parce qu'on ne fait rien créer aux élèves qu'ils sont incapables d'une certaine disposition d'esprit si nécessaire à la pratique de la philosophie. J'insiste : il n'y a aucune difficulté à maintenir une définition de philosophie comme « activité de création de concepts » et à penser l'enseignement de la philosophie pour tous. Ce lien intime entre construction de concepts et pédagogie est précisément la raison pour laquelle Deleuze théorisa à juste titre le «statut pédagogique du concept $»{ }^{29}$ À ce titre seulement, on cesse d'écarteler les différents sens du mot culture : la culture, comme dépôt de biens symboliques, devient source et produit de la culture de soi, de la transformation de soi, car on ne se transforme jamais mieux comme sujet qu'en transformant des objets - surtout culturels.

28. Sur l'importance du « faire » et l'égale dignité dans la création, cf. Rancière J. (2004) [1987]. Le Maitre ignorant. Paris : Fayard, «10/18 », p. 109-120.

29. Pour une démonstration complète du corrélat entre apprentissage et création de concept, je me permets de renvoyer à une enquête précédente : Charbonnier S. (2009). Deleuze pédagogue. Paris: L'Harmattan, p. 200-203. 
La culture de soi est une technique artisanale de confrontation avec un matériau qui résiste - biens culturels - si tant est que soit laissée la possibilité de travailler ce matériau et de s'essayer à le manipuler en tout sens.

Sébastien Charbonnier

Centre de Recherche en Éducation de Nantes (CREN) - université de Nantes. 